\title{
Evidence for the use of probiotics and prebiotics in inflammatory bowel disease: a review of clinical trials
}

\author{
Charlotte Hedin ${ }^{1}$, Kevin Whelan ${ }^{1}$ and James O. Lindsay ${ }^{2 *}$ \\ ${ }^{1}$ Nutritional Sciences Division, King's College London, London SE1 9NH, UK \\ ${ }^{2}$ Barts and the London NHS Trust, The Royal London Hospital, London E1 1BB, UK
}

\begin{abstract}
Human subjects and their enteric microbiota have evolved together to reach a state of mutual tolerance. Mounting evidence from both animal models and human studies suggests that inflammatory bowel disease (IBD) represents a malfunction of this relationship. The enteric microecology therefore represents an attractive therapeutic target with few side effects. Probiotics and prebiotics have been investigated in clinical trials as treatments for IBD, with conflicting results. The evidence for the use of probiotics in the management of pouchitis is persuasive and several studies indicate their effectiveness in ulcerative colitis. Trials of probiotics and prebiotics in Crohn's disease are less convincing. However, methodologies vary widely and a range of probiotic, prebiotic and combination (synbiotic) treatments have been tested in a variety of patient groups with an assortment of end points. Conclusions about any one treatment in a specific patient group can therefore only be drawn on evidence from relatively small numbers of patients. The present article reviews the role of the intestinal microbiota in the pathogenesis of IBD and addresses the clinical evidence for the therapeutic manipulation of bowel microbiota using probiotics, prebiotics and synbiotics in IBD.
\end{abstract}

Prebiotic: Probiotic: Ulcerative colitis: Crohn's disease: Pouchitis

The ability to define self from non-self and thereby maintain the integrity of the individual in the face of interference from other organisms is the defining property of an immune system. In the gut, however, this vital role must be executed in the setting of conflicting demands of constant exposure to ingested elements of the host's environment and antigens from commensal organisms at a mucosa adapted to permit uptake and absorption of nutrients. The operation of gastrointestinal immunity must therefore be particularly subtle in order to discriminate between pathogens to be excluded and symbiotic commensals to be tolerated. The gut immune system is unique in being able to contain organisms that if encountered in another bodily compartment would evoke an aggressive and damaging response. There is mounting evidence that the inflammatory bowel diseases (IBD) represent a malfunction of this singular attribute of tolerance to the commensal microbiota, which focuses attention on this relationship as a potential therapeutic target.

IBD comprises a spectrum of disorders characterised by inflammation, ulceration and stricturing of the gastrointestinal tract that results in symptoms of abdominal pain, diarrhoea and gastrointestinal bleeding. The two major phenotypes are ulcerative colitis (UC) and Crohn's disease (CD), both of which are chronic, relapsing and remitting diseases. UC causes continuous mucosal inflammation from the anal verge and is confined to the colon, whereas CD presents with discontinuous patchy transmural inflammation throughout the intestinal tract, with a predilection for the terminal ileum.

Conventional drug therapy is associated with a number of disadvantages, including a considerable burden of side effects and less than comprehensive efficacy, with a marked percentage of patients still requiring surgery to resect the affected gut. In $\mathrm{UC}$, for example, a colectomy and ileal pouch anal anastamosis may be required either for refractory or fulminant disease or to reduce the risk of colon cancer in patients with dysplasia. Unfortunately, symptoms of inflammation can recur within the pouch resulting in the syndrome of pouchitis.

\section{Inflammatory bowel disease and the gastrointestinal microbiota}

The causes of IBD have not been fully elucidated, but are thought to involve both genetic and environmental factors. 
More recently, a number of observations have suggested that the intestinal microbiota may drive intestinal inflammation. First, experimental animal models of IBD remain healthy when reared in a germ-free environment and develop inflammation only after colonisation with commensal bacteria (Onderdonk et al. 1981; Sellon et al. 1998). Second, higher concentrations of bacteroides and enterobacteria are found in regions of inflamed mucosa in CD (Swidsinski et al. 2002). Third, in both CD (Harper et al. 1985; D'Haens et al. 1998) and pouchitis (de Silva et al. 1991) disease activity deteriorates when the faecal stream is surgically restored to previously-defunctioned intestine, implying that the lumen contents are necessary for the development of inflammation. Finally, the association between ileal $\mathrm{CD}$ and mutations in the bacterialsensing caspase-activating recruitment domain 15 gene implicate bacterial recognition as a central pathogenic process (Ogura et al. 2001).

In contrast, there is also evidence that the commensal microbiota protect the mucosa from inflammation by decreasing intestinal permeability, increasing epithelial defence mechanisms and promoting an immunoregulatory acquired immune response (Madsen et al. 1999; Macpherson \& Uhr, 2004; Rakoff-Nahoum et al. 2004). The mechanisms by which commensal microbiota interact with the gut immune system have been the focus of recent interest. There is evidence that metabolites produced by bacteria may interact directly with gut epithelial cells to enhance mucosal integrity (Venkatraman et al. 2000; Stempelj et al. 2007). In addition, commensal bacteria may compete with pro-inflammatory species to decrease access to the mucosa (Lee et al. 2003). Finally, microbial signature molecules, termed pathogen-associated molecular patterns, can interact with pattern recognition receptors such as toll-like receptors expressed on many host cells, including both epithelial cells and lamina propria dendritic cells (Stagg et al. 2003).

Despite this evidence for a microbial influence in pathogenesis, drugs conventionally used to induce and maintain remission in IBD, such as aminosalicylates (5-aminosalicylic acid drugs), corticosteroids, immunosuppressants (azathioprine and methotrexate) and infliximab (a chimeric monoclonal antibody), primarily act to suppress the enhanced immune response and do not affect the microbiota. Antibiotic-mediated microbial manipulation has some efficacy, especially in active $\mathrm{CD}$ and pouchitis, but cannot be used to maintain remission because of lack of long-term efficacy and side effects (Sutherland et al. 1991; Borgaonkar et al. 2000). None of these treatments is effective in all patients and all treatments are associated with major side effects. Therapies such as prebiotics and probiotics that selectively manipulate the gastrointestinal microbiota present a novel treatment option with a low side-effect burden.

Probiotics are living microbes that when introduced to the gut are capable of benefiting the host, and include organisms such as lactobacilli, bifidobacteria, Grampositive cocci, enterococci and yeast species such as Saccharomyces boulardii (Fuller, 1989). Prebiotics are selectively fermented short-chain carbohydrates that allow specific changes both in the composition and/or activity of the gastrointestinal microbiota that confers health benefit, and include fructo-oligosaccharides and galactooligosaccharides (Gibson \& Roberfroid, 1995). Combinations of probiotics and prebiotics are termed synbiotics. Evidence from animal models of IBD indicates that probiotics can alter the intestinal microbiota and ameliorate disease (Sartor, 2004). Similarly, prebiotics have been shown to enhance lumenal immunoregulatory bacteria, reduce the activity of pro-inflammatory transcription factors (e.g. NF-אB) and attenuate inflammation (Holma et al. 2002; Cavin et al. 2005). In addition, prebiotics produce SCFA, such as acetate and butyrate (Probert et al. 2004), that inhibit mucosal inflammation, impacting on both epithelial and dendritic cell function (Kinoshita et al. 2002; Millard et al. 2002).

The present review aims to assess the evidence that these observations from in vitro experiments and animal models can be put into clinical practice. The evidence presented relates to trials that have assessed these therapies in terms of clinical outcomes in IBD, and the data extracted and presented are the clinical end points in each study.

\section{Probiotics and prebiotics in pouchitis}

The most compelling evidence for the use of probiotics in IBD comes from randomised double-blind placebocontrolled trials of VSL\#3 (a mixture of four species of lactobacilli, three species of bifidobacteria and Streptococcus thermophilus; Vsl Pharmaceuticals Inc., Gaithersburg, MD, USA) in patients with pouchitis (Table 1). Gionchetti et al. (2000) have assessed the efficacy of VSL\#3 as a maintenance treatment in forty patients with chronic relapsing pouchitis after antibiotic-induced remission. After 4 months fewer relapses were found to occur in the intervention group than in the control group. Moreover, all patients were subsequently found to relapse 3 months after cessation of VSL\#3. The same group (Gionchetti et al. 2003) have assessed VSL\#3 in the primary prevention of pouchitis in forty patients following surgery. The incidence of pouchitis was found to be reduced and the quality of life improved in the VSL\#3-treated group compared with the placebo group at the end of the intervention period; these beneficial effects were associated with faecal colonisation with the probiotics. Finally, a further study (Mimura et al. 2004) has confirmed the effectiveness of VSL\#3 as maintenance therapy in patients with recurrent or chronic pouchitis. Importantly, these studies demonstrate high relapse rates of pouchitis in the placebo group, perhaps reflecting intensive patient follow-up resulting in the detection of relapse that may have otherwise remained subclinical.

In contrast, Shen et al. (2005) have reported no significant benefit of VSL\#3 in maintaining antibiotic-induced remission in thirty-one patients. After 8 months twentythree patients had discontinued VSL\#3 because of symptom recurrence and two had discontinued because of side effects. In the six patients who remained on VSL\#3 endoscopic evidence of mild to moderate pouchitis was found to persist even though symptom scores were not significantly different from baseline. Although the fact that 
Table 1. Clinical outcomes of published studies investigating the efficacy of probiotics and prebiotics in the treatment of pouchitis

\begin{tabular}{|c|c|c|c|c|c|c|c|c|}
\hline \multirow[b]{2}{*}{ Reference } & \multirow[b]{2}{*}{$n$} & \multirow[b]{2}{*}{ Trial design } & \multicolumn{2}{|l|}{ Study groups } & \multirow{2}{*}{$\begin{array}{l}\text { Duration } \\
\text { (months) }\end{array}$} & \multicolumn{2}{|c|}{ Relapse rate (\%) } & \multirow[b]{2}{*}{$P$} \\
\hline & & & Intervention (daily dose) & Control & & Intervention & Control & \\
\hline Gionchetti et al. (2000) & 40 & $\mathrm{R}, \mathrm{DB}$ & VSL\#3 (6g) & PI & 9 & 15 & 100 & $<0.001$ \\
\hline Welters et al. (2002) & 20 & $\mathrm{R}, \mathrm{DB}, \mathrm{CO}$ & Inulin $(24 \mathrm{~g})$ & $\mathrm{PI}$ & $2 \cdot 2$ & NR & NR & NR \\
\hline Friedman \& George (2000) & 10 & $\mathrm{OL}$ & $\begin{array}{l}\text { LGG (one tablet) plus } \\
\text { FOS (one tablet) }\end{array}$ & - & & & - & \\
\hline Gionchetti et al. (2003) & 40 & $\mathrm{R}, \mathrm{DB}$ & VSL\#3 (3g) & $\mathrm{PI}$ & 12 & 10 & 40 & $<0.05$ \\
\hline Kuisma et al. (2003) & 20 & $\mathrm{R}, \mathrm{DB}$ & LGG $\left(>10^{10} \mathrm{CFU}\right)$ & $\mathrm{PI}$ & 3 & NR & NR & NR \\
\hline Gosselink et al. (2004) & 117 & OL & LGG (300 mg) & $\mathrm{HC}$ & 36 & 8 & 35 & 0.01 \\
\hline Mimura et al. (2004) & 36 & $\mathrm{R}, \mathrm{DB}$ & VSL\#3 $(6 \mathrm{~g})$ & $\mathrm{PI}$ & 12 & 15 & 94 & $<0.01$ \\
\hline Laake et al. (2005) & 51 & OL & Fermented milk $(500 \mathrm{ml})$ & - & 1 & NR & - & - \\
\hline Shen et al. (2005) & 31 & OL & VSL\#3 $(6 \mathrm{~g})$ & - & 8 & 81 & - & - \\
\hline
\end{tabular}

$\mathrm{R}$, randomised; DB, double blind; CO, cross-over study; OL, open label; VSL\#3, a mixture of four species of lactobacilli, three species of bifidobacteria and Streptococcus thermophilus; LGG, Lactobacillus rhamnosus GG; FOS, fructo-oligosaccharide; PI, placebo; HC, historical controls; CFU, colony-forming units; NR, not reported.

patients purchased, stored and administered the VSL\#3 themselves may have resulted in lower compliance, this methodology may more faithfully reproduce patients' use of probiotics outside clinical trials.

Trials of other probiotics in the management of pouchitis have yielded mixed results. One observational study of patients receiving Lactobacillus rhamnosus $G G$ (LGG) after pouch formation (Gosselink et al. 2004) has reported a lower rate of pouchitis than in historical controls. However, Kuisma et al. (2003) have found no difference in mean pouchitis scores between placebo and LGG-treated groups at the end of a 3-month study period, despite an increase in faecal lactobacilli:anaerobes. Finally, a reduction in endoscopic and clinical disease activity associated with an increase in faecal probiotic species has been demonstrated (Laake et al. 2005) in fifty-one patients with pouchitis after surgery for ulcerative colitis who consumed a fermented milk containing lactobacilli and bifidobacteria. These studies suggest that therapeutic benefit requires a combination of probiotic species (as with VSL\#3) or that the component(s) responsible for the anti-inflammatory effect in combination preparations have specific properties that monotherapy probiotics do not. This concept supports the use of prebiotics that increase concentrations of several commensal immunoregulatory bacteria.

Two studies have examined the use of prebiotics or synbotics in pouchitis. Ten patients with antibioticrefractory or antibiotic-dependent pouchitis treated with a combination of LGG and fructo-oligosaccharide in an open-label study were reported to experience complete clinical and endoscopic remission (Friedman \& George, 2000). Welters et al. (2002) have reported that intake of inulin is associated with a decrease in histological and endoscopy scores in twenty patients in a cross-over study with a 4-week wash-out period between 3-week study phases. No patient had overt clinical pouchitis at enrolment and no change in clinical activity scores was detected, although overall pouchitis disease activity index was found to be significantly reduced during the inulin period $(P=0 \cdot 01)$. Prebiotic use was shown to be associated with a reduction in the faecal concentration of Bacteroides fragilis $(P=0.02)$, but had no effect on lactobacilli or bifidobacteria. In addition, inulin was found to increase faecal butyrate concentrations $(P=0 \cdot 01)$ and reduce $\mathrm{pH}$, with no effect on secondary bile acid concentration.

\section{Probiotics and prebiotics as maintenance therapy in ulcerative colitis}

Many trials have examined the use of probiotics to maintain remission in patients with UC. Three controlled trials (Kruis et al. 1997, 2004; Rembacken et al. 1999) have demonstrated that Escherichia coli Nissle 1917 has similar efficacy to conventional 5-aminosalicylic acid (mesalazine) treatment, but the evidence to support the use of other probiotic species is less persuasive (Table 2). Kruis et al. (1997) have demonstrated equivalence of mesalazine and E. coli Nissle 1917 in patients with UC in remission over 12 weeks. However, studying the maintenance of remission over a short follow-up period is of limited clinical applicability. Rembacken et al. (1999) have treated patients for a 12-month period and have also demonstrated equivalence of mesalazine v. E. coli Nissle 1917. Remission was induced using standard medical treatment (including topical and systemic corticosteroids) alongside the study intervention. No significant difference was found in the time to achieve remission or mean duration of remission, although the lack of a placebo group may make it difficult to distinguish a small difference in effectiveness from the effect of potent doses of steroid. Finally, no significant difference was found in the rate of relapse in a study comparing E. coli Nissle 1917 with mesalazine in 327 patients using no concomitant medication (Kruis et al. 2004). Probiotic therapies such as E. coli Nissle 1917 that have equivalent efficacy but fewer side effects than conventional drug therapies present an appealing alternative for patients and physicians.

Several studies examining the use of lactobacilli or bifidobacteria as maintenance treatment in UC have demonstrated conflicting results. In patients randomised to three open-label arms (LGG $v$. mesalazine $v$. LGG plus mesalazine) it was demonstrated (Zocco et al. 2006) that both the lactobacillus arms experience a prolonged 
Table 2. Clinical outcomes of published studies investigating the efficacy of probiotics in maintenance of remission in ulcerative colitis

\begin{tabular}{|c|c|c|c|c|c|c|c|c|}
\hline \multirow[b]{3}{*}{ Reference } & \multirow[b]{3}{*}{$n$} & \multirow{3}{*}{$\begin{array}{l}\text { Trial } \\
\text { design }\end{array}$} & \multicolumn{2}{|c|}{ Study groups } & \multirow{3}{*}{$\begin{array}{l}\text { Duration } \\
\text { (months) }\end{array}$} & \multirow{2}{*}{\multicolumn{2}{|c|}{ Relapse rate (\%) }} & \multirow[b]{3}{*}{$P$} \\
\hline & & & \multirow{2}{*}{$\begin{array}{l}\text { Intervention } \\
\text { (dose/d) }\end{array}$} & \multirow{2}{*}{$\begin{array}{l}\text { Comparator } \\
\text { (dose/d) }\end{array}$} & & & & \\
\hline & & & & & & Intervention & Comparator & \\
\hline Kruis et al. (1997) & 120 & $\mathrm{R}, \mathrm{DB}, \mathrm{DD}$ & E. coli Nissle $(200 \mathrm{mg})$ & Mesalazine $(1.5 \mathrm{~g})$ & 3 & 16 & 11 & NS \\
\hline $\begin{array}{l}\text { Rembacken } \\
\text { et al. (1999) }\end{array}$ & 116 & $\mathrm{R}, \mathrm{DB}, \mathrm{DD}$ & E. coli Nissle $\left(>10^{10} \mathrm{CFU}\right)$ & Mesalazine $(2.4 \mathrm{~g})$ & 12 & 32 & 25 & 0.05 \\
\hline Venturi et al. (1999) & 20 & OL & VSL\#3 (6g) & - & 12 & 20 & - & - \\
\hline $\begin{array}{l}\text { Ishikawa } \\
\text { et al. (2003) }\end{array}$ & 21 & $\mathrm{R}$ & Fermented milk (100 ml) & $\mathrm{PI}$ & 12 & 27 & 90 & $<0.01$ \\
\hline Cui et al. (2004) & 30 & $\mathrm{R}, \mathrm{DB}$ & Bifidobacteria $(1 \cdot 26 \mathrm{~g})$ & $\mathrm{PI}$ & 8 & 20 & 93 & $<0.01$ \\
\hline Kruis et al. (2004) & 327 & $\mathrm{R}, \mathrm{DB}, \mathrm{DD}$ & E. coli Nissle $(200 \mathrm{mg})$ & Mesalazine $(500 \mathrm{mg})$ & 12 & 36 & 34 & SE 0.03 \\
\hline Zocco et al. (2006) & 180 & $\mathrm{R}, \mathrm{OL}$ & $\begin{array}{l}\text { LGG }\left(>10^{10} \mathrm{CFU}\right) \\
\text { LGG }\left(>10^{10} \mathrm{CFU}\right)+ \\
\text { mesalazine }(2 \cdot 4 \mathrm{~g})\end{array}$ & Mesalazine $(2 \cdot 4 \mathrm{~g})$ & 12 & $\begin{array}{l}15 \\
17\end{array}$ & 20 & $0 \cdot 77$ \\
\hline $\begin{array}{l}\text { Shanahan } \\
\text { et al. (2006) }\end{array}$ & 157 & $\mathrm{R}, \mathrm{DB}$ & $\begin{array}{l}\text { L. salivarius }\left(10^{9} \mathrm{CFU}\right) \\
\text { B. infantis }\left(10^{9} \mathrm{CFU}\right)\end{array}$ & $\mathrm{PI}$ & 12 & NR & NR & NR \\
\hline
\end{tabular}

$\mathrm{R}$, randomised; DB, double blind; DD, double dummy; OL, open label; E. coli N, Escherichia coli Nissle 1917; CFU, colony-forming units; VSL\#3, a mixture of four species of lactobacilli, three species of bifidobacteria and Streptococcus thermophilus; LGG, Lactobacillus rhamnosus GG; L. salivarius, Lactobacillus salivarius; B. infantis, Bifidobacterium infantis; PI, placebo; NR, not reported; SE, significant equivalence.

relapse-free time compared with 5-aminosalicylic acid treatment alone, despite no significant differences in overall relapse rates and clinical, histological or endoscopy scores. In a study of thirty patients with UC in medicallyinduced remission (Cui et al. 2004) those receiving supplements of bifidobacteria were found to have fewer relapses during the 2-month follow-up period than those receiving placebo ( $20 \%$ v. $93 \%$ respectively). In addition, those receiving the probiotic were found to have increases in the concentration of faecal lactobacilli and bifidobacteria, a reduction in the expression of the proinflammatory transcription factor NF- $\mathrm{NB}$ and enhancement of anti-inflammatory cytokine release. Similarly, Ishikawa et al. (2003) have demonstrated a reduction in the number of disease exacerbations in a group of Japanese patients receiving fermented milk containing Bifidobacterium breve, Bifidobacterium bifidum and Lactobacillus acidophilus compared with placebo. However, this clinical benefit was not found to be associated with an increase in steroid-free remission or endoscopic improvement in disease activity. In contrast, a recently presented study (Shanahan et al. 2006) comparing Lactobacillus salivarius with Bifidobacterium infantis or placebo in 157 patients with UC in medically-induced remission has demonstrated no significant benefit of either of the probiotics when compared with placebo. Finally, treatment with VSL\#3 to maintain remission in UC (Venturi et al. 1999) was found to result in an increase in faecal concentrations of VSL\#3 bacteria and a reduction in faecal $\mathrm{pH}$. At the end of the study only four of twenty patients had experienced relapse.

There are few data on the efficacy of prebiotics or synbiotics in the maintenance of remission in UC.

\section{Probiotics and prebiotics to treat active ulcerative colitis}

Four diverse studies have examined the use of probiotics to treat active UC (Table 3). Tursi et al. (2004) have compared low-dose balsalazide + VSL\#3 v. medium-dose balsalazide alone $v$. mesalazine alone in patients with mildto moderately-active UC. Remission rates and time to remission were found to be shortest in the combination group. These results suggest that probiotics may augment the effect of 5-aminosalicylic acid drugs, although the balsalazide doses used in this study were lower than those generally used in clinical practice. In a second study in which clinical benefit of VSL\#3 was also demonstrated (Bibiloni et al. 2005) VSL\#3-specific organisms were detected in only three of eleven patients after microbiological analysis of mucosal biopsies. This finding suggests that the clinical effect observed was not the result of a direct influence of VSL\#3-derived organisms at the mucosa.

Efficacy of direct delivery of the probiotic to the colon with E. coli Nissle 1917 enemas in left-sided UC has been demonstrated (Matthes et al. 2006). A significant dose-dependent response was found and the time to remission was also reported to be shortest in the group receiving the highest dose of enema. A fourth probiotic was studied by Kato et al. (2004), who treated active UC with fermented milk (B. breve strain Yakult, B. bifidum strain Yakult and a L. acidophillus strain). Although no difference was found in either remission rates or histological and endoscopy scores between the groups, the clinical activity scores were found to be lower in the treatment group than in the placebo group at the end of the study period.

A series of small open-label studies have evaluated a prebiotic germinated barley foodstuff (a glutamine-rich protein and dietary fibre, mainly hemicellulose) and have found evidence for therapeutic efficacy. For example, when the germinated barley foodstuff was administered to ten patients with mild- to moderately-active UC (Mitsuyama et al. 1998) a significant decrease was found in mean clinical activity score after 4 weeks of treatment $(P<0.05)$ associated with increases in faecal SCFA concentration. 
Table 3. Clinical outcomes of published studies investigating the efficacy of probiotics in induction of remission in patients with active ulcerative colitis

\begin{tabular}{|c|c|c|c|c|c|c|c|c|}
\hline \multirow[b]{3}{*}{ Reference } & \multirow[b]{3}{*}{$n$} & \multirow{3}{*}{$\begin{array}{c}\text { Trial } \\
\text { design }\end{array}$} & \multicolumn{2}{|c|}{ Study groups } & \multirow{3}{*}{$\begin{array}{c}\text { Duration } \\
\text { (weeks) }\end{array}$} & \multirow{2}{*}{\multicolumn{2}{|c|}{ Remission rate (\%) }} & \multirow[b]{3}{*}{$P$} \\
\hline & & & Intervention & Comparator & & & & \\
\hline & & & (dose/d) & $($ dose/d) & & Intervention & Comparator & \\
\hline Mitsuyama et al. (1998) & 10 & OL & $\begin{array}{l}\text { Germinated barley } \\
\text { foodstuff }(30 \mathrm{~g})\end{array}$ & - & 4 & NR & - & NR \\
\hline Tursi et al. (2004) & 90 & $\mathrm{R}, \mathrm{OL}$ & $\begin{array}{l}\text { VSL\#3 plus balsalazide } \\
(2.25 \mathrm{~g})\end{array}$ & $\begin{array}{l}\text { Balsalazide }(4.5 \mathrm{~g}) \\
\text { Mesalazine }(2.4 \mathrm{~g})\end{array}$ & 8 & 80 & $\begin{array}{l}77 \\
53\end{array}$ & 0.02 \\
\hline Kato et al. (2004) & 20 & $R, D B$ & Fermented milk (100 ml) & $\mathrm{Pl}$ & 12 & 40 & 30 & NS \\
\hline Biblioni et al. (2005) & 34 & $\mathrm{OL}$ & VSL\#3 (>10 $\left.{ }^{10} \mathrm{CFU}\right)$ & - & 6 & 53 & - & - \\
\hline Furrie et al. (2005) & 18 & $\mathrm{R}, \mathrm{DB}$ & $\begin{array}{l}\text { Synergy } 1(6 \mathrm{~g}) \text { and } \\
\text { B. longum }\left(>10^{11} \mathrm{CFU}\right)\end{array}$ & $\mathrm{PI}$ & 4 & NR & NR & NR \\
\hline Matthes et al. (2006) & 90 & $\mathrm{R}, \mathrm{DB}$ & 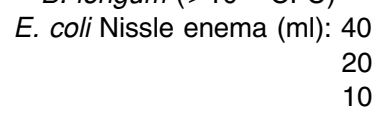 & $\mathrm{PI}$ & 4 & $\begin{array}{l}53 \\
44 \\
27\end{array}$ & 18 & 0.04 \\
\hline
\end{tabular}

OL, open label; R, randomised; DB, double blind; VSL\#3, a mixture of four species of lactobacilli, three species of bifidobacteria and Streptococcus thermophilus; CFU, colony-forming units; B. longum, Bifidobacterium longum; E. coli N, Escherichia coli Nissle 1917; DB, double blind; PI, placebo; NR, not reported.

Table 4. Clinical outcomes of published studies investigating the efficacy of probiotics and prebiotics in maintenance of remission in patients with Crohn's disease

\begin{tabular}{|c|c|c|c|c|c|c|c|c|}
\hline \multirow[b]{3}{*}{ Reference } & \multirow[b]{3}{*}{$n$} & \multirow{3}{*}{$\begin{array}{l}\text { Trial } \\
\text { design }\end{array}$} & \multicolumn{2}{|c|}{ Study groups } & \multirow{3}{*}{$\begin{array}{l}\text { Duration } \\
\text { (months) }\end{array}$} & \multirow{2}{*}{\multicolumn{2}{|c|}{ Relapse rate (\%) }} & \multirow[b]{3}{*}{$P$} \\
\hline & & & \multirow{2}{*}{$\begin{array}{l}\text { Intervention } \\
\text { (dose/d) }\end{array}$} & \multirow{2}{*}{$\begin{array}{l}\text { Comparator } \\
\text { (dose/d) }\end{array}$} & & & & \\
\hline & & & & & & Intervention & Comparator & \\
\hline Guslandi et al. (2000) & 32 & $\mathrm{R}, \mathrm{OL}$ & $\begin{array}{l}\text { S. boulardii }(1 \mathrm{~g}) \\
\text { plus mesalazine }(2 \mathrm{~g})\end{array}$ & Mesalazine $(3 \mathrm{~g})$ & 6 & 6 & 38 & 0.04 \\
\hline Campieri et al. (2000) & 40 & $\mathrm{R}, \mathrm{OL}$ & VSL\#3 (6g) & Mesalamine $(4 \mathrm{~g})$ & 12 & 20 & 40 & NR \\
\hline Prantera et al. (2002) & 45 & $\mathrm{R}, \mathrm{DB}$ & LGG $(4.92 \mathrm{~g})$ & $\mathrm{PI}$ & 12 & 17 & 11 & 0.30 \\
\hline Schultz et al. (2004) & 11 & R, DB & LGG $\left(>10^{9} \mathrm{CFU}\right)$ & $\mathrm{PI}$ & 6 & 60 & 67 & NS \\
\hline Bousvaros et al. (2005) & 75 & $\mathrm{R}, \mathrm{DB}$ & LGG $\left(>10^{9} \mathrm{CFU}\right)$ & $\mathrm{PI}$ & 24 & 31 & 17 & $0 \cdot 18$ \\
\hline Marteau et al. (2006) & 98 & $\mathrm{R}, \mathrm{DB}$ & L. johnsonii (>10 $\left.0^{9} \mathrm{CFU}\right)$ & $\mathrm{PI}$ & 6 & 49 & 64 & $0 \cdot 15$ \\
\hline Van Gossum et al. (2007) & 70 & R, DB & L. johnsonii (>10 $\left.0^{9} \mathrm{CFU}\right)$ & $\mathrm{PI}$ & 3 & 15 & 14 & 0.91 \\
\hline Chermesh et al. (2007) & 30 & $R, D B$ & Synbiotic $2000^{*}$ & $\mathrm{PI}$ & 24 & 25 & 20 & NS \\
\hline
\end{tabular}

$\mathrm{R}$, randomised; OL, open label; DB, double blind; S. boulardii, Saccharomyces boulardii; VSL\#3, a mixture of four species of lactobacilli, three species of bifidobacteria and Streptococcus thermophilus; LGG, Lactobacillus rhamnosus GG; CFU, colony-forming units; L. johnsonii, Lactobacillus johnsonii; PI, placebo; NR, not reported.

*Pediacoccus pentoseceus, Lactobacillus raffinolactis, Lactobacillus paracasei susp paracasei 19 , Lactobacillus plantarum, $2.5 \mathrm{~g} \beta$-glucans, $2 \cdot 5 \mathrm{~g}$ inulin, $2.5 \mathrm{~g}$ pectin, $2.5 \mathrm{~g}$ resistant starch.

A pilot study of eighteen patients in a randomised double-blind double-dummy study over 1 month (Furrie et al. 2005) has suggested that synbiotics may have a role in reducing inflammation in UC. A non-significant trend in favour of the combination of oligofructose and inulin and a probiotic (Bifidobacterium longum) was observed on histological and sigmoidoscopic assessment but clinical measures were not found to be different. However, mucosal-associated bifidobacteria concentrations were found to increase in association with a decrease in both proinflammatory cytokines such as TNF $\alpha$ and IL- $1 \alpha$ and antimicrobial human $\beta$-defensin peptides. It is disappointing that the observed alterations in mucosal cytokine balance did not translate into more clinically-important changes in symptoms or endoscopic appearance. It may be that this rapid change in cytokine expression would give rise to a more clinically-relevant change if treatment were sustained for a longer period.

\section{Probiotics and prebiotics to maintain remission in Crohn's disease}

Evidence for the use of probiotics as maintenance therapy in $\mathrm{CD}$ is not persuasive, with only two studies reporting positive results (Table 4). A study comparing S. boulardii + the antibiotic mesalazine with mesalazine alone (Guslandi et al. 2000) has shown fewer relapses in the former group in patients with medically-induced remission of CD. Campieri et al. (2000) have shown benefit of VSL\#3 in preventing post-operative recurrence in forty patients randomised to 3 months of rifaximin followed by 9 months of VSL\#3 or to 12 months of mesalazine. 
Table 5. Clinical outcomes of published studies investigating the efficacy of probiotics and prebiotics in induction of remission in patients with active Crohn's disease

\begin{tabular}{|c|c|c|c|c|c|c|c|c|}
\hline \multirow[b]{3}{*}{ Reference } & \multirow[b]{3}{*}{$n$} & \multirow{3}{*}{$\begin{array}{c}\text { Trial } \\
\text { design }\end{array}$} & \multicolumn{2}{|c|}{ Study groups } & \multirow{3}{*}{$\begin{array}{l}\text { Duration } \\
\text { (weeks) }\end{array}$} & \multirow{2}{*}{\multicolumn{2}{|c|}{ Remission rate (\%) }} & \multirow[b]{3}{*}{$P$} \\
\hline & & & \multirow{2}{*}{$\begin{array}{l}\text { Intervention } \\
(\text { dose/d) }\end{array}$} & \multirow{2}{*}{$\begin{array}{l}\text { Comparator } \\
\text { (dose/d) }\end{array}$} & & & & \\
\hline & & & & & & Intervention & Comparator & \\
\hline Malchow (1997) & 28 & $\mathrm{R}, \mathrm{DB}$ & E. coli $\mathrm{N}(100 \mathrm{mg})$ & $\mathrm{PI}$ & 12 & 75 & 92 & NS \\
\hline Gupta et al. (2000) & 4 & $\mathrm{OL}$ & LGG $\left(>10^{10} \mathrm{CFU}\right)$ & - & 24 & 100 & - & - \\
\hline Lindsay et al. (2006) & 10 & $\mathrm{OL}$ & FOS $(15 \mathrm{~g})$ & - & 3 & 40 & - & - \\
\hline
\end{tabular}

R, randomised; DB, double blind; OL, open label; E. coli N, Escherichia coli Nissle 1917; LGG, Lactobacillus rhamnosus GG; CFU, colony-forming units; FOS, fructo-oligosaccharide; PI, placebo.

Conversely, three studies using LGG (Prantera et al. 2002; Schultz et al. 2004; Bousvaros et al. 2005) have not confirmed the effectiveness of this probiotic as a maintenance strategy after surgically- or medically-induced remission. No significant differences in clinical or endoscopic recurrence rates were found between patients receiving LGG or placebo to maintain surgical remission (Prantera et al. 2002). Similarly, Schultz et al. (2004) have shown no significant effect of LGG in maintaining remission induced with antibiotics and steroids. Finally, no significant difference in time to relapse was found between probiotics or placebo (inulin) in a paediatric population with medically-induced remission (Bousvaros et al. 2005). In this study few patients were found to have high concentrations of faecal lactobacilli $(7 \%$ and $20 \%$ in the intervention and placebo groups respectively). The study was terminated early because of lack of effect and poor recruitment. It is important to note that the placebo (inulin) is a prebiotic that could therefore mask any difference in efficacy between the groups. It could even be argued that the non-significant trend towards fewer relapses in the placebo group could relate to the higher dose of inulin administered, although this explanation is unlikely at the low doses employed.

Finally, two randomised double-blind placebo-controlled studies (Marteau et al. 2006; Van Gossum et al. 2007) have reported no effect of Lactobacillus johnsonii LA1 in preventing recurrence in patients with $\mathrm{CD}$ in surgicallyinduced remission. Marteau et al. (2006) have found no significant difference in endoscopic recurrence in comparison with placebo 6 months after surgery. Likewise, Van Gossum et al. (2007) have reported no significant difference from placebo in endoscopy scores or clinical relapse rates after 3 months of treatment.

The use of prebiotic therapies in the maintenance of remission in $\mathrm{CD}$ has not been studied extensively. In patients with $\mathrm{CD}$ who have undergone ileal resection treatment with Synbiotic 2000 (Pediacoccus pentoseceus, Lactobacillus raffinolactis, Lactobacillus paracasei susp paracasei 19, Lactobacillus plantarum, $2.5 \mathrm{~g} \beta$-glucans, $2.5 \mathrm{~g}$ inulin, $2.5 \mathrm{~g}$ pectin, $2.5 \mathrm{~g}$ resistant starch) was reported to have no impact on maintaining remission when compared with placebo (Chermesh et al. 2007). It is notable that the investigators had intended to enrol twice as many patients, but were unable to do so because of reluctance of patients and physicians to risk exposure to the placebo arm.

\section{Probiotics and prebiotics to treat active Crohn's disease}

Two studies have evaluated probiotics in patients with active CD (Malchow, 1997; Gupta et al. 2000), but neither study has demonstrated convincing efficacy, in part because of concomitant drug prescription and small numbers of patients (Table 5). Malchow (1997) has compared E. coli Nissle 1917 with placebo in patients with active CD who also received the steroid prednisolone, $60 \mathrm{mg}$ daily for 11 weeks, to induce remission and then continued with probiotics or placebo during a 12-month maintenance phase. The proportion of patients achieving remission and time to remission was found to be similar in the two groups, suggesting that the remission was mostly attributable to steroid use. In the maintenance phase there was a non-significant trend towards decreased relapse rates in the E. coli group $v$. the placebo group. Gupta et al. (2000) have examined the effects of LGG in four children with steroid refractory $\mathrm{CD}$, two of whom were taking concomitant metronidazole. Colonisation with LGG and a sustained reduction in disease activity associated with improved intestinal permeability was demonstrated in all patients, suggesting a mechanism for the therapeutic effect.

Prebiotics have also been investigated in the treatment of CD. Lindsay et al. (2006) have found that fructooligosaccharide reduces disease activity in active CD. As in healthy controls (Langlands et al. 2004), fructooligosaccharide was shown to increase faecal bifidobacteria concentrations, although no corresponding change in mucosal-associated bifidobacteria was found. However, a significant increase was found in mucosal bifidobacteria in those patients entering remission. Evidence was found of an immunoregulatory shift in dendritic cell activity, with an increase in the proportion of IL-10-positive dendritic cells $(P=0 \cdot 06)$, and enhanced toll-like receptor 2 and toll-like receptor 4 expression $(P=0.086$ and $P<0.001$ respectively). A placebo-controlled trial to confirm the benefit of fructo-oligosaccharide in active $\mathrm{CD}$ is underway.

\section{Limitations to research on probiotics and probiotics in inflammatory bowel disease}

Interpretation of the current literature on probiotics and prebiotics in IBD is undermined by marked heterogeneity between trials frequently precluding meta-analysis. Variables include the choice of probiotic or prebiotic studied 
and their dose, the trial design and the outcome measures reported. The populations studied differ, with some trials enrolling patients with active disease and others studying maintenance of remission induced by antibiotics, conventional drug treatment or surgery. Few studies stratify for disease distribution, and none have reported the prevalence of genotypes that may impact on the response to therapies manipulating the microbiota. Most studies have enrolled small numbers of patients, which limits statistical power and is of particular relevance given the high placebo response rates seen in clinical trials of IBD (Su et al. 2004, 2007). Finally, no study has included details of the patients' diet, which could exert a marked influence on the efficacy of microbial therapies.

The precise mechanisms of action of probiotics and prebiotics remain to be elucidated. For example, it is not clear whether intestinal colonisation with probiotic species is necessary, as some studies demonstrating clinical efficacy have not demonstrated such colonisation (Bibiloni et al. 2005). Further research is required to determine whether prebiotics exert their effect via increased numbers of bacteria that are recognised by intestinal immune cells or via effects of SCFA on the mucosa. In vitro studies examining the effect of prebiotics in enterocyte models may reveal direct effects on the mucosa. Investigation of changes in immune cell phenotype on exposure to prebiotics and/or bacteria may elucidate such relationships.

\section{Conclusions}

There is a well established link between the intestinal microbiota and the inflammation associated with IBD, with evidence for both pro-inflammatory and regulatory effects. Thus, selective manipulation of the microbiota is an attractive therapeutic strategy for the treatment of disease and maintenance of remission.

The evidence for the use of probiotics in IBD is strongest in the case of pouchitis, particularly for the use of VSL\#3. In addition, E. coli Nissle 1917 appears to be at least equivalent to 5-aminosalicylic acid treatment in $\mathrm{UC}$ and may be useful in the form of enemas for distal disease. However, studies of probiotics in CD have been disappointing, and a recent Cochrane systematic review (Rolfe et al. 2006) has concluded that their use could not be recommended on the available evidence. Prebiotics are frequently evaluated as part of a synbiotic combination, making it difficult to isolate their individual effects. However, few adverse events have been reported for either probiotics or prebiotics in any of these studies, confirming the safety of these treatments.

At present, there is some evidence to support the use of probiotics and prebiotics in IBD, although large trials using standardised methodology are required to confirm this evidence. However, the investigation of the therapeutic application of these treatments increases understanding of the role of the gastrointestinal microecology in the pathogenesis of IBD. With improved knowledge of the mechanisms by which the gastrointestinal mirobiota determine gut immune responses, clinical research will be better focused to select appropriate investigational probiotic treatments and patient groups, and trial outcomes can be more meaningfully translated into clinical practice.

\section{Acknowledgements}

The authors would like to acknowledge the collaborative work of Dr Andrew Stagg, Professor Stella Knight (Imperial College, London) and Professor Alastair Forbes (University College London, London), as well as funding from the Broad Medical Research Programme.

\section{References}

Bibiloni R, Fedorak RN, Tannock GW, Madsen KL, Gionchetti $\mathrm{P}$, Campieri M et al. (2005) VSL\#3 probiotic-mixture induces remission in patients with active ulcerative colitis. American Journal of Gastroenterology 100, 1539-1546.

Borgaonkar M, MacIntosh D, Fardy J, Simms L (2000) Antituberculous Therapy for Maintaining Remission of Crohn's Disease. The Cochrane Database of Systematic Reviews 2000, issue 2, CD000299. Chichester, West Sussex: John Wiley and Sons Ltd.

Bousvaros A, Guandalini S, Baldassano RN, Botelho C, Evans J, Ferry GD et al. (2005) A randomized, double-blind trial of Lactobacillus GG versus placebo in addition to standard maintenance therapy for children with Crohn's disease. Inflammatory Bowel Diseases 11, 833-839.

Campieri M, Rizzello F, Venturi A, Gilberto P, Ugolini F, Helwig U, Amadini C, Romboli E \& Gionchetti P (2000) Combination of antibiotic and probiotic treatment is efficacious in prophylaxis of post-operative recurrence of Crohn's disease: A randomized controlled study vs mesalamine. Gastroenterology 118, G4179.

Cavin C, Delannoy M, Malnoe A, Debefve E, Touche A, Courtois D \& Schilter B (2005) Inhibition of the expression and activity of cyclooxygenase- 2 by chicory extract. Biochemical and Biophysical Research Communications 327, 742-749.

Chermesh I, Tamir A, Reshef R, Chowers Y, Suissa A, Katz D, Gelber M, Halpern Z, Bengmark S \& Eliakim R (2007) Failure of synbiotic 2000 to prevent postoperative recurrence of Crohn's disease. Digestive Diseases and Sciences 52, 385-389.

Cui HH, Chen CL, Wang JD, Yang YJ, Cun Y, Wu JB, Liu YH, Dan HL, Jian YT \& Chen XQ (2004) Effects of probiotic on intestinal mucosa of patients with ulcerative colitis. World Journal of Gastroenterology 10, 1521-1525.

D'Haens GR, Geboes K, Peeters M, Baert F, Penninckx F \& Rutgeerts P (1998) Early lesions of recurrent Crohn's disease caused by infusion of intestinal contents in excluded ileum. Gastroenterology 114, 262-267.

de Silva HJ, Millard PR, Soper N, Kettlewell M, Mortensen N \& Jewell DP (1991) Effects of the faecal stream and stasis on the ileal pouch mucosa. Gut 32, 1166-1169.

Friedman G \& George J (2000) Treatment of refractory 'pouchitis' with prebiotic and probiotic therapy. Gastroenterology 118, G4167.

Fuller R (1989) Probiotics in man and animals. Journal of Applied Bacteriology 66, 365-378.

Furrie E, Macfarlane S, Kennedy A, Cummings JH, Walsh SV, O'Neil DA \& Macfarlane GT (2005) Synbiotic therapy (Bifidobacterium longum/Synergy 1) initiates resolution of inflammation in patients with active ulcerative colitis: a randomised controlled pilot trial. Gut 54, 242-249. 
Gibson GR \& Roberfroid MB (1995) Dietary modulation of the human colonic microbiota: introducing the concept of prebiotics. Journal of Nutrition 125, 1401-1412.

Gionchetti P, Rizzello F, Helwig U, Venturi A, Lammers KM, Brigidi P, Vitali B, Piggoli G, Miglioli M \& Campieri M (2003) Prophylaxis of pouchitis onset with probiotic therapy: a double-blind, placebo-controlled trial. Gastroenterology 124, 1202-1209.

Gionchetti P, Rizzello F, Venturi A, Brigidi P, Matteuzzi D, Bazzocchi G, Piggoli G, Miglioli M \& Campieri M (2000) Oral bacteriotherapy as maintenance treatment in patients with chronic pouchitis: a double-blind, placebo-controlled trial. Gastroenterology 119, 305-309.

Gosselink MP, Schouten WR, van Lieshout LM, Hop WC, Laman JD \& Ruseler-van Embden JG (2004) Delay of the first onset of pouchitis by oral intake of the probiotic strain Lactobacillus rhamnosus GG. Diseases of the Colon and Rectum 47 , 876-884.

Gupta P, Andrew H, Kirschner BS \& Guandalini S (2000) Is lactobacillus GG helpful in children with Crohn's disease? Results of a preliminary, open-label study. Journal of Pediatric Gastroenterology and Nutrition 31, 453-457.

Guslandi M, Mezzi G, Sorghi M \& Testoni PA (2000) Saccharomyces boulardii in maintenance treatment of Crohn's disease. Digestive Diseases and Sciences 45, 14621464.

Harper PH, Lee EC, Kettlewell MG, Bennett MK \& Jewell DP (1985) Role of the faecal stream in the maintenance of Crohn's colitis. Gut 26, 279-284.

Holma R, Juvonen P, Asmawi MZ, Vapaatalo H \& Korpela R (2002) Galacto-oligosaccharides stimulate the growth of bifidobacteria but fail to attenuate inflammation in experimental colitis in rats. Scandinavian Journal of Gastroenterology 37, 1042-1047.

Ishikawa H, Akedo I, Umesaki Y, Tanaka R, Imaoka A \& Otani $T$ (2003) Randomized controlled trial of the effect of bifidobacteria-fermented milk on ulcerative colitis. Journal of the American College of Nutrition 22, 56-63.

Kato K, Mizuno S, Umesaki Y, Ishii Y, Sugitani M, Imaoka A, Otsuka M, Hasunuma O, Kurihara R, Iwasaki A \& Arakawa Y (2004) Randomized placebo-controlled trial assessing the effect of bifidobacteria-fermented milk on active ulcerative colitis. Alimentary Pharmacology and Therapeutics 20, 11331141.

Kinoshita M, Suzuki Y \& Saito Y (2002) Butyrate reduces colonic paracellular permeability by enhancing PPARgamma activation. Biochemical and Biophysical Research Communications 293, 827-831.

Kruis W, Fric P, Pokrotnieks J, Lukas M, Fixa B, Kascak M et al. (2004) Maintaining remission of ulcerative colitis with the probiotic Escherichia coli Nissle 1917 is as effective as with standard mesalazine. Gut 53, 1617-1623.

Kruis W, Schutz E, Fric P, Fixa B, Judmaier G \& Stolte M (1997) Double-blind comparison of an oral Escherichia coli preparation and mesalazine in maintaining remission of ulcerative colitis. Alimentary Pharmacology and Therapeutics 11, 853858.

Kuisma J, Mentula S, Jarvinen H, Kahri A, Saxelin M \& Farkkila M (2003) Effect of Lactobacillus rhamnosus GG on ileal pouch inflammation and microbial flora. Alimentary Pharmacology and Therapeutics 17, 509-515.

Laake KO, Bjorneklett A, Aamodt G, Aabakken L, Jacobsen M, Bakka A \& Vatn MH (2005) Outcome of four weeks' intervention with probiotics on symptoms and endoscopic appearance after surgical reconstruction with a J-configurated ileal-pouch-anal-anastomosis in ulcerative colitis. Scandinavian Journal of Gastroenterology 40, 43-51.
Langlands SJ, Hopkins MJ, Coleman N \& Cummings JH (2004) Prebiotic carbohydrates modify the mucosa associated microflora of the human large bowel. Gut 53, 1610-1616.

Lee YK, Puong KY, Ouwehand AC \& Salminen S (2003) Displacement of bacterial pathogens from mucus and Caco-2 cell surface by lactobacilli. Journal of Medical Microbiology 2, 925-930.

Lindsay JO, Whelan K, Stagg AJ, Gobin P, Al-Hassi HO, Rayment N, Kamm MA, Knight SC \& Forbes A (2006) Clinical, microbiological, and immunological effects of fructooligosaccharide in patients with Crohn's disease. Gut 55, 348355.

Macpherson AJ \& Uhr T (2004) Induction of protective $\operatorname{IgA}$ by intestinal dendritic cells carrying commensal bacteria. Science 303, 1662-1665.

Madsen KL, Doyle JS, Jewell LD, Tavernini MM \& Fedorak RN (1999) Lactobacillus species prevents colitis in interleukin 10 gene-deficient mice. Gastroenterology 116, 1107-1114.

Malchow HA (1997) Crohn's disease and Escherichia coli. A new approach in therapy to maintain remission of colonic Crohn's disease? Journal of Clinical Gastroenterology 25, 653-658.

Marteau P, Lemann M, Seksik P, Laharie D, Colombel JF, Bouhnik Y et al. (2006) Ineffectiveness of Lactobacillus johnsonii LA1 for prophylaxis of postoperative recurrence in Crohn's disease: a randomised, double blind, placebo controlled GETAID trial. Gut 55, 842-847.

Matthes H, Krummenerl T, Giensch M, Wolff C \& Schulze J (2006) Treatment of mild to moderate acute attacks of distal ulcerative colitis with rectally-administered E. coli Nissle 1917: Dose-dependent efficacy. Gastroenterology 130, Suppl. 2, A119.

Millard AL, Mertes PM, Ittelet D, Villard F, Jeannesson P \& Bernard J (2002) Butyrate affects differentiation, maturation and function of human monocyte-derived dendritic cells and macrophages. Clinical and Experimental Immunology 130, 245-255.

Mimura T, Rizzello F, Helwig U, Poggioli G, Schreiber S, Talbot IC, Nicholls RJ, Gionchetti P, Campieri M \& Kamm MA (2004) Once daily high dose probiotic therapy (VSL\#3) for maintaining remission in recurrent or refractory pouchitis. Gut 53, 108-114.

Mitsuyama K, Saiki T, Kanauchi O, Iwanaga T, Tomiyasu N, Nishiyama T et al. (1998) Treatment of ulcerative colitis with germinated barley foodstuff feeding: a pilot study. Alimentary Pharmacology and Therapeutics 12, 1225-1230.

Ogura Y, Bonen DK, Inohara N, Nicolae DL, Chen FF, Ramos R et al. (2001) A frameshift mutation in NOD2 associated with susceptibility to Crohn's disease. Nature 411, 603-606.

Onderdonk AB, Franklin ML \& Cisneros RL (1981) Production of experimental ulcerative colitis in gnotobiotic guinea pigs with simplified microflora. Infection and Immunity 32, 225231.

Prantera C, Scribano ML, Falasco G, Andreoli A \& Luzi C (2002) Ineffectiveness of probiotics in preventing recurrence after curative resection for Crohn's disease: a randomised controlled trial with Lactobacillus GG. Gut 51, 405-409.

Probert HM, Apajalahti JH, Rautonen N, Stowell J \& Gibson GR (2004) Polydextrose, lactitol, and fructo-oligosaccharide fermentation by colonic bacteria in a three-stage continuous culture system. Applied and Environmental Microbiology $\mathbf{7 0}$, 4505-4511.

Rakoff-Nahoum S, Paglino J, Eslami-Varzaneh F, Edberg S \& Medzhitov R (2004) Recognition of commensal microflora by toll-like receptors is required for intestinal homeostasis. Cell 118, 229-241.

Rembacken BJ, Snelling AM, Hawkey PM, Chalmers DM \& Axon AT (1999) Non-pathogenic Escherichia coli versus 
mesalazine for the treatment of ulcerative colitis: a randomised trial. Lancet 354, 635-639.

Rolfe VE, Fortun PJ, Hawkey CJ \& Bath-Hextall F (2006) Probiotics for Maintenance of Remission in Crohn's Disease. The Cochrane Database of Systematic Reviews 2006, issue 4, CD004826. Chichester, West Sussex: John Wiley and Sons Ltd.

Sartor RB (2004) Therapeutic manipulation of the enteric microflora in inflammatory bowel diseases: antibiotics, probiotics, and prebiotics. Gastroenterology 126, 1620-1633.

Schultz M, Timmer A, Herfarth HH, Sartor RB, Vanderhoof JA \& Rath HC (2004) Lactobacillus GG in inducing and maintaining remission of Crohn's disease. BMC Gastroenterology 4, 5 .

Sellon RK, Tonkonogy S, Schultz M, Dieleman LA, Grenther W, Balish E, Rennick DM \& Sartor RB (1998) Resident enteric bacteria are necessary for development of spontaneous colitis and immune system activation in interleukin-10-deficient mice. Infection and Immunity 66, 5224-5231.

Shanahan F, Guarner F, von Wright A, Vilpponen-Salmela T, O'Donoghue D, Kiely B et al. (2006) A one year, randomised, double-blind, placebo controlled trial of a lactobacillus or a bifidobacterium probiotic for maintenance of steroid-induced remission of ulcerative colitis. Gastroenterology 130, Suppl. 2, A44.

Shen B, Brzezinski A, Fazio VW, Remzi FH, Achkar JP, Bennett AE, Sherman K \& Lashner BA (2005) Maintenance therapy with a probiotic in antibiotic-dependent pouchitis: experience in clinical practice. Alimentary Pharmacology and Therapeutics 22, 721-728.

Stagg AJ, Hart AL, Knight SC \& Kamm MA (2003) The dendritic cell: its role in intestinal inflammation and relationship with gut bacteria. Gut 52, 1522-1529.

Stempelj M, Kedinger M, Augenlicht L \& Klampfer L (2007) The essential role of the JAK/STAT1 signaling pathway in the expression of INOS in intestinal epithelial cells and its regulation by butyrate. Journal of Biological Chemistry 282, 9797-9804.

Su C, Lewis JD, Goldberg B, Brensinger C \& Lichtenstein GR (2007) A meta-analysis of the placebo rates of remission and response in clinical trials of active ulcerative colitis. Gastroenterology 132, 516-526.
Su C, Lichtenstein GR, Krok K, Brensinger CM \& Lewis JD (2004) A meta-analysis of the placebo rates of remission and response in clinical trials of active Crohn's disease. Gastroenterology 126, 1257-1269.

Sutherland L, Singleton J, Sessions J, Hanauer S, Krawitt E, Rankin G et al. (1991) Double blind, placebo controlled trial of metronidazole in Crohn's disease. Gut 32, 1071-1075.

Swidsinski A, Ladhoff A, Pernthaler A, Swidsinski S, LoeningBaucke V, Ortner M, Weber J, Hoffmann U, Schreiber S, Dietel M \& Lochs H (2002) Mucosal flora in inflammatory bowel disease. Gastroenterology 122, 44-54.

Tursi A, Brandimarte G, Giorgetti GM, Forti G, Modeo ME \& Gigliobianco A (2004) Low-dose balsalazide plus a highpotency probiotic preparation is more effective than balsalazide alone or mesalazine in the treatment of acute mild-to-moderate ulcerative colitis. Medical Science Monitor 10, I126-I131.

Van Gossum A, Dewit O, Louis E, de Hertogh G, Baert F, Fontaine F, DeVos M, Enslen M, Paintin M \& Franchimont D (2007) Multicenter randomized-controlled clinical trial of probiotics (Lactobacillus johnsonii, LA1) on early endoscopic recurrence of Crohn's disease after ileo-caecal resection. Inflammatory Bowel Diseases 13, 135-142.

Venkatraman A, Ramakrishna BS, Pulimood AB, Patra S \& Murthy S (2000) Increased permeability in dextran sulphate colitis in rats: time course of development and effect of butyrate. Scandinavian Journal of Gastroenterology 35, 10531059.

Venturi A, Gionchetti P, Rizzello F, Johansson R, Zucconi E, Brigidi P, Matteuzzi D \& Campieri M (1999) Impact on the composition of the faecal flora by a new probiotic preparation: preliminary data on maintenance treatment of patients with ulcerative colitis. Alimentary Pharmacology and Therapeutics 13, 1103-1108.

Welters CF, Heineman E, Thunnissen FB, van den Bogaard AE, Soeters PB \& Baeten CG (2002) Effect of dietary inulin supplementation on inflammation of pouch mucosa in patients with an ileal pouch-anal anastomosis. Diseases of the Colon and Rectum 45, 621-627.

Zocco MA, dal Verme LZ, Cremonini F, Piscaglia AC, Nista EC, Candelli M et al. (2006) Efficacy of Lactobacillus GG in maintaining remission of ulcerative colitis. Alimentary Pharmacology and Therapeutics 23, 1567-1574. 